\title{
Activation of $\sigma^{28}$-dependent transcription in Escherichia coli by the cyclic AMP receptor protein requires an unusual promoter organization
}

Kerry Hollands, David J. Lee, Georgina S. Lloyd and Stephen J. W. Busby*

School of Biosciences, University of Birmingham, Edgbaston, Birmingham, UK.

\section{Summary}

The Escherichia coli aer regulatory region contains a single promoter that is recognized by RNA polymerase containing the flagellar sigma factor, $\sigma^{28}$. Expression from this promoter is dependent on direct activation by the cyclic AMP receptor protein, which binds to a target centred 49.5 base pairs upstream from the transcript start. Activator-dependent transcription from the aer promoter was reconstituted in vitro, and a tethered inorganic nuclease was used to find the position of the C-terminal domains of the RNA polymerase $\alpha$ subunits in transcriptionally competent open complexes. We report that the ternary activator-RNA polymerase-aer promoter open complex is organized differently from complexes at previously characterized promoters. Among other E. coli promoters recognized by RNA polymerase containing $\sigma^{28}$, only the trg promoter is activated directly by the cyclic AMP receptor protein. The organization of the different promoter elements and the activator binding site at the trg promoter is the same as at the aer promoter, suggesting a common activation mechanism.

\section{Introduction}

The cyclic AMP receptor protein (CRP, also known as the catabolite activator protein, CAP) is a global transcription factor, which plays a central role in the control of metabolism in Escherichia coli and other enteric bacteria (Kolb et al., 1993; Barrett et al., 2005). CRP, which is functional as a homodimer, recognizes 22 bp target sequences, with the consensus 5'-AAATGTGATCTAGATCACATTT- $3^{\prime}$. At

Accepted 30 September, 2009. *For correspondence. E-mail s.j.w. busby@bham.ac.uk; Tel. (+44) 121414 5439; Fax (+44) 121414 5925.

Re-use of this article is permitted in accordance with the Terms and Conditions set out at http://www3.interscience.wiley.com/ authorresources/onlineopen.html most target promoters studied to date, CRP activates transcription by making one or more direct contacts with RNA polymerase, and there appear to be two major classes of simple CRP-activated promoters (Busby and Ebright, 1999). At Class I promoters, CRP binds upstream of the promoter -35 element, at a site centred at position -61.5 (i.e. between base pairs 61 and 62 upstream from the transcript start), or further upstream, and an activating region (AR1) in the downstream subunit of the CRP dimer makes contact with the C-terminal domain of one of the two RNA polymerase $\alpha$ subunits $(\alpha C T D$ ). At Class II promoters, CRP binds at a target that overlaps the promoter -35 element and is usually centred at position -41.5 . AR1 in the upstream subunit of the CRP dimer interacts with $\alpha C T D$, while a second activating region (AR2) in the downstream subunit interacts with the $\mathrm{N}$-terminal domain of one of the two RNA polymerase $\alpha$ subunits ( $\alpha$ NTD) (Busby and Ebright, 1999).

Although the mechanisms of activation by CRP at both classes of promoter have been scrutinized in detail, most studies have focused on a small number of natural and synthetic model promoters, so it is unclear whether the findings apply to all target promoters. Genomic approaches have now identified scores of new targets for CRP (Tan et al., 2001; Brown and Callan, 2004; Gosset et al., 2004; Zheng et al., 2004; Grainger et al., 2005). This affords an opportunity to study CRP-dependent regulation at a range of naturally occurring promoters, and to uncover novel mechanisms of regulation by CRP. Previously, Hollands et al. (2007) investigated the action of CRP at 11 such uncharacterized targets in the E. coli K-12 genome. One of these was located in the regulatory region of the aer gene, which encodes an aerotaxis sensor protein that controls movement of bacterial cells in response to the availability of oxygen and other electron acceptors in the environment (Bibikov et al., 1997; Rebbapragada et al., 1997; Taylor et al., 1999). CRP binding upstream of aer was first detected by Grainger et al. (2005) in a whole genome chromatin immunoprecipitation analysis, and it was subsequently shown that CRP activates transcription by binding to a single DNA site in the aer regulatory region (Hollands et al., 2007).

Recent transcriptome analyses have indicated that expression of aer in both E. coli and Salmonella enterica 
serovar Typhimurium requires an alternative $\sigma$ factor, $\sigma^{28}$ (Frye et al., 2006; Zhao et al., 2007). Recall that the RNA polymerase $\sigma$ subunit is a dissociable promoter specificity factor that binds to core RNA polymerase (E) to form the RNA polymerase holoenzyme $(E \sigma)$, which can recognize promoter sequences and initiate transcription (Burgess et al., 1969). Most bacteria contain multiple $\sigma$ factors that recognize different promoter -10 and -35 elements. $A$ primary $\sigma$ factor $\left(\sigma^{70}\right.$ in $E$. coli) drives the transcription of genes with 'housekeeping' functions, while a number of alternative $\sigma$ factors direct transcription of particular sets of genes in response to environmental signals or stresses, or function to control development (Ishihama, 2000; Gruber and Gross, 2003). $\sigma^{28}$, which is encoded by the fliA gene, is the most widely distributed alternative $\sigma$ factor (Koo et al., 2009; Smith and Hoover, 2009), and controls the transcription of operons required for flagellar filament assembly and for the regulation of motility and chemotaxis in a large number of Gram-positive and Gramnegative bacteria (Chilcott and Hughes, 2000).

Most studies on transcription activation by CRP have been concerned with promoters recognized by RNA holoenzyme containing $\sigma^{70}\left(E \sigma^{70}\right)$. Here, we report the first investigation into the direct regulation by CRP of transcription by RNA polymerase containing $\sigma^{28}\left(E \sigma^{28}\right)$. We show that aer is transcribed from a single $\sigma^{28}$-dependent promoter that is activated by CRP binding at a location different from any previously characterized CRP-activated promoter. We also show that CRP directly activates transcription from a second $\sigma^{28}$-dependent promoter that has a similar organization.

\section{Results and discussion}

\section{Transcription from the aer regulatory region requires both $C R P$ and $\sigma^{28}$ in vivo}

To study the effects of CRP and $\sigma^{28}$ on expression of aer, we cloned a DNA fragment covering the aer gene regulatory region (aer200; Hollands et al., 2007) into a low-copynumber lac expression vector, pRW50, and we measured the activity of the resulting aer200::lacZ fusion in E. coli $\mathrm{K}-12 \Delta$ lac strain M182 and derivatives containing deletions of either the crp or fliA gene. Results presented in Fig. 1A (black lines) show that, in M182, there is a large increase in promoter activity during late exponential phase that decreases on entry into stationary phase. This is consistent with the findings of Barembruch and Hengge (2007), who observed a similar pattern of expression for the $\sigma^{28}$ dependent flgM promoter, and correlates with an accumulation of $\sigma^{28}$ protein during late exponential phase followed by a decline in $\sigma^{28}$ levels once the culture enters stationary phase (K. Hollands, unpubl. data; Barembruch and Hengge, 2007). In the $\Delta$ fliA and $\Delta c r p$ backgrounds
A
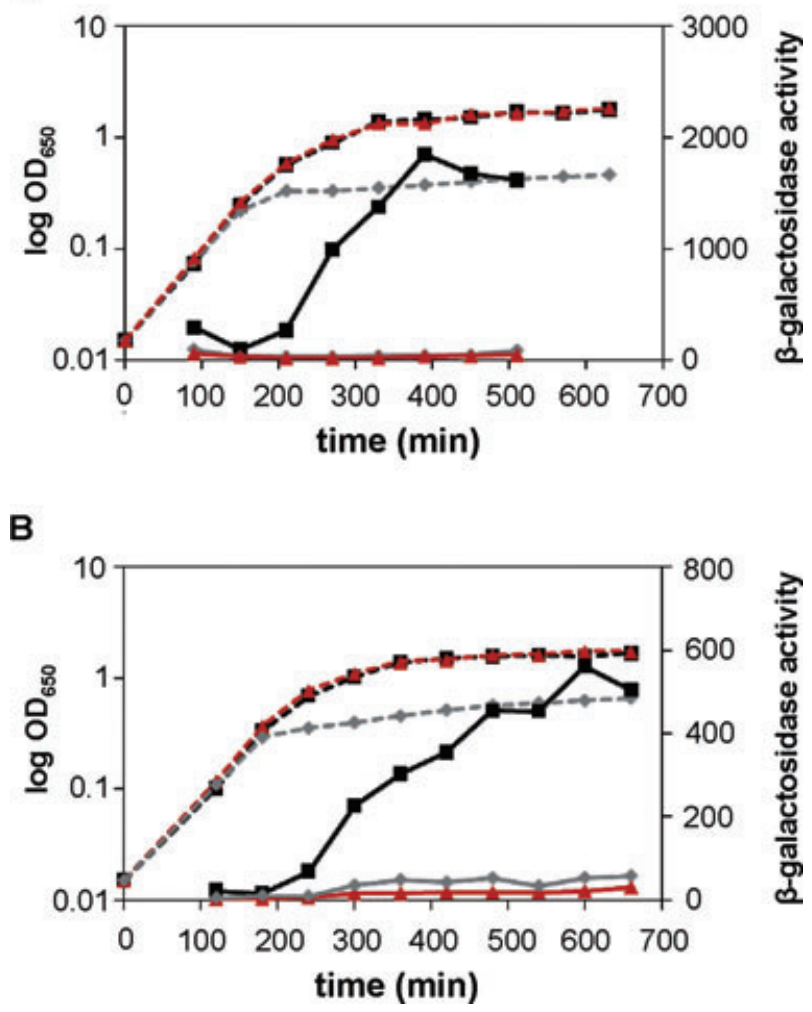

Fig. 1. CRP and $\sigma^{28}$ dependency of aer promoter activity throughout growth.

A. Requirement for CRP and $\sigma^{28}$ in a strain expressing $\sigma^{28}$ from the chromosomal fliA promoter. The figure shows $\mathrm{OD}_{650}$ values (dashed lines) and $\beta$-galactosidase activities (in Miller units; solid lines) measured throughout growth in Escherichia coli K-12 strain M182 (black lines), M182 $\Delta$ crp (grey lines) or M182 $\Delta$ fliA (red lines), each carrying the aer200::lacZ fusion cloned in pRW50.

B. Requirement for CRP and $\sigma^{28}$ in a strain expressing $\sigma^{28}$ from a CRP-independent promoter on plasmid pKXH100. The figure shows $\mathrm{OD}_{650}$ values (dashed lines) and $\beta$-galactosidase activities (in Miller units; solid lines) measured in strain M182 $\Delta$ fliA containing pKXH100 ( $\mathrm{CRP}^{+} \mathrm{FliA}^{+}$black lines), strain M182 $\Delta$ fliA $\Delta$ crp

containing pKXH100 (CRP- FliA $^{+}$grey lines) or strain M182 $\Delta$ fliA containing 'empty' $\mathrm{pET} 21 \mathrm{a}\left(\mathrm{CRP}^{+} \mathrm{FliA}^{\text {'; }}\right.$ red lines), each carrying the aer200::/acZ fusion cloned in pRW50.

(Fig. 1A, red and grey lines), promoter activity remained at a basal level throughout the growth cycle. This confirms that both CRP and $\sigma^{28}$ are essential for expression from the aer regulatory region in vivo. However, this experiment is complicated by the fact that $\sigma^{28}$ expression is dependent on CRP. This is because CRP is required to activate transcription of the fIhDCoperon that encodes an essential activator of transcription from the fliA promoter (Soutourina et al., 1999). Indeed, Western blot analysis confirms that no $\sigma^{28}$ protein is present in strain M182 $\Delta c r p$ (Fig. S1, lanes 1-3).

To investigate the action of CRP at the aer regulatory region, independent of the indirect effect of CRP on $\sigma^{28}$ levels, we established an experimental system in which expression of $\sigma^{28}$ is uncoupled from CRP. To do this, we used $\Delta$ fliA derivatives of M182 and M182 $\Delta$ crp that had 
A

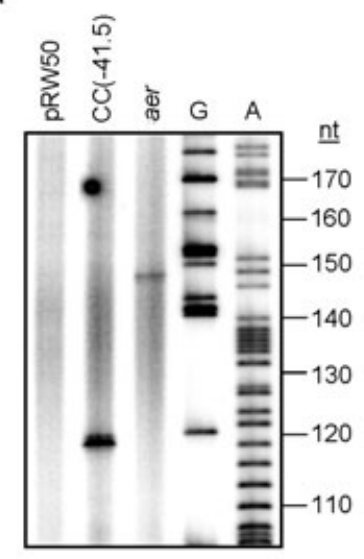

B

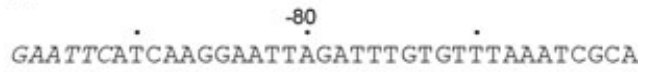

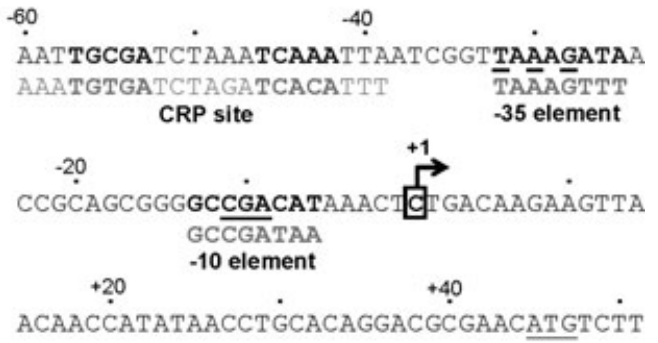

$+60$

CTCATCCGTATGTCAAGCTT

Fig. 2. Identification of the aer transcript start site.

A. The figure shows the result of primer extension analysis using RNA extracted from strain M182, carrying the aer200 fragment cloned in pRW50, grown aerobically to mid-exponential phase $\left(\mathrm{OD}_{650}\right.$ 0.4-0.6) in LB medium. Control primer extension reactions were also carried out using RNA extracted from M182 cells containing 'empty' pRW50, or pRW50 carrying the CC(-41.5) promoter, whose transcript start site is known, and which gives a primer extension product of $118 \mathrm{nt}$ in pRW50. The sizes of primer extension products were determined by calibration against sequencing reactions (lanes $G$ and $A$ ).

$B$. The figure shows the base sequence of the non-template strand of the aer200 promoter fragment used in this work. The transcript start site proposed here is boxed, and the aer translation start codon is underlined. The proposed -10 and -35 octamer elements of the $\sigma^{28}$-dependent aer promoter, and the DNA site for CRP, are highlighted in bold. The consensus sequence for each DNA element is indicated in grey below the sequence (Busby and Ebright, 1999; Koo et al., 2009). Bases in the -10 and -35 elements that were targeted for mutational analysis are underlined in bold. The EcoRI and Hindlll sites flanking the aer200 fragment are shown in italics, and the sequence is numbered with the aer transcript start site as +1 .

been transformed with pKXH100, which encodes fliA under the control of a CRP-independent promoter. Western blot analysis confirms that, in this system, expression of $\sigma^{28}$ does not require CRP (Fig. S1, lanes 4-6). We measured expression of the aer200::/ac Z fusion in pRW50 in these strains. Data illustrated in Fig. 1B show that, in M182 $\triangle$ fliA pKXH100, the activity of the aer200::lacZ fusion follows a similar pattern to that in strain M182 (which expresses fliA from the chromosome), except that the increase in promoter activity occurs later in growth, once the culture begins to enter stationary phase. This correlates with a delayed increase in $\sigma^{28}$ protein levels in this background (K. Hollands, unpubl. results). In the absence of CRP, promoter activity remains low throughout the growth cycle, showing that the requirement for CRP for expression from the aer regulatory region is independent of the effect of CRP on $\sigma^{28}$ levels. We conclude that CRP must function directly at the aer regulatory region, and this is consistent with the previous observation that introducing mutations into the DNA target for CRP upstream of aer prevents CRP-dependent activation of the aer200::lacZ fusion (Hollands et al., 2007).

aer is transcribed from a single $\sigma^{28}$-dependent promoter in vivo

Although the aer regulatory region has been predicted as a target for $\mathrm{E}^{28}$ (Park et al., 2001; Frye et al., 2006; Zhao et al., 2007), the promoter determinants required for transcription initiation have not been identified experimentally. To define the DNA elements required for $\sigma^{28}$-dependent transcription of aer, we began by mapping the aer transcript start site by primer extension analysis, using the aer200 promoter fragment cloned in pRW50. This yielded a single extension product approximately 148 nucleotides in length (Fig. 2A), which places the transcript start point at the position labelled +1 in Fig. 2B. This falls 6 bp downstream from the -10 octamer element for a $\sigma^{28}$-dependent promoter predicted by Park et al. (2001). To examine the importance of this promoter, we constructed derivatives of the aer200 fragment containing point mutations in the putative -10 and -35 elements (Table 1 and Fig. 2B). In the -10 element, we targeted the highly conserved 5'-CGA-3' motif, from positions -11 to -9 , because mutations in this motif result in a loss of $\sigma^{28}$-dependent transcription from other $\sigma^{28}$-dependent promoters, both in vivo and in vitro (Yu et al., 2006; Wozniak and Hughes, 2008). In the -35 octamer, we targeted positions $-32 \mathrm{~T}$ and $-30 \mathrm{~A}$, which are also highly conserved and are important for $\sigma^{28}$-dependent transcription from the Salmonella flgM promoter, and position -28, which has more minor effects on flgM promoter activity (Wozniak and Hughes, 2008). Each mutant promoter fragment was cloned into pRW50, and expression of the resulting promoter::lac $Z$ fusions was measured in the $\mathrm{CRP}^{+} \mathrm{FliA}^{+}, \mathrm{CRP}^{-} \mathrm{FliA}^{+}$and $\mathrm{CRP}^{+} \mathrm{FliA}^{-}$ backgrounds. Results listed in Table 1 show that the sub- 
Table 1. Effect of mutations in the -10 and -35 elements on aer promoter activity.

\begin{tabular}{|c|c|c|c|c|}
\hline \multirow[b]{2}{*}{ Promoter fragment } & \multirow[b]{2}{*}{ Promoter sequence } & \multicolumn{3}{|c|}{$\beta$-Galactosidase activity } \\
\hline & & $\mathrm{CRP}^{+} \mathrm{FliA}^{+}$ & $\mathrm{CRP}^{-} \mathrm{FliA}^{+}$ & $\mathrm{CRP}^{+} \mathrm{FliA}^{-}$ \\
\hline aer200 & TAAAGATA- $n_{11}-G C C G A C A T$ & $223 \pm 27$ & $53 \pm 6$ & $12 \pm 1$ \\
\hline aer206 & TAAAGATA-n $n_{11}-$ GCGCTCAT & $12 \pm 1$ & $32 \pm 1$ & $11 \pm 1$ \\
\hline aer213 & CAAAGATA- $n_{11}-G C \overline{C G A C A T}$ & $23 \pm 2$ & $31 \pm 1$ & $23 \pm 1$ \\
\hline aer214 & TATAGATA-n ${ }_{11}-$ GCCGACAT & $26 \pm 1$ & $43 \pm 1$ & $14 \pm 1$ \\
\hline aer224 & TAĀAAATA-n ${ }_{11}-$ GCCGACAT & $50 \pm 2$ & $36 \pm 1$ & $12 \pm 1$ \\
\hline
\end{tabular}

The table lists $\beta$-galactosidase activities (in Miller units) measured in strain M182 $\Delta$ fliA containing pKXH100 (CRP ${ }^{+}$FliA $\left.^{+}\right)$, strain M182 $\Delta$ fliA $\Delta c r p$ containing pKXH100 (CRP' FliA') or strain M182 $\Delta$ fliA containing 'empty' pET21a ( $\mathrm{CRP}^{+} \mathrm{FliA}^{-}$), each carrying different aer promoter::/acZ fusions cloned in pRW50 and grown to late exponential phase $\left(\mathrm{OD}_{650} 0.9-1.1\right)$ in $\mathrm{LB}$ medium. The aer200 fragment carries the wild-type aer promoter, the aer206 fragment carries three point mutations in the proposed -10 element, and the aer213, aer214 and aer224 fragments carry single point mutations in the proposed -35 octamer. The sequence of the -10 and -35 elements of the $\sigma^{28}$-dependent aer promoter is listed for each fragment, and the location of base changes in each of the mutant promoter derivatives is underlined. The consensus sequence for a $\sigma^{28}$-dependent promoter is shown below the table. Data listed are averages from at least three independent experiments, shown \pm one standard deviation.

stitutions in the -10 element had the greatest effect on promoter activity, reducing expression from the aer regulatory region to the level observed in the absence of $\sigma^{28}$. Mutations at positions $-32,-30$ and -28 in the -35 element also severely reduced promoter activity. We conclude that the proposed -10 and -35 elements are essential for $\sigma^{28}$-dependent transcription of aer, and, together with the transcript start site data, this argues that aer is expressed from a single promoter, at least under the conditions tested here.

\section{Transcription initiation at the aer promoter in vitro}

Next, we sought to confirm our in vivo findings by examining the $\sigma$ factor selectivity and CRP dependence of the aer promoter in vitro. We began by cloning the aer200 fragment upstream of the $\lambda$ oop terminator in plasmid pSR, and tested the ability of purified $E \sigma^{28}$ and $E \sigma^{70}$ to drive transcription from the aer promoter in an in vitro multiround transcription assay, in the presence and absence of purified CRP and CAMP (Fig. 3A). In this system, transcription initiating at the aer promoter terminates at the

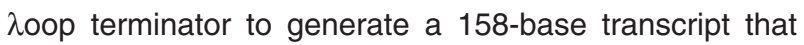
can be identified by electrophoresis. In the presence of $E \sigma^{28}$, a single transcript was observed (Fig. 3A, lanes 3-12). At low $E \sigma^{28}$ concentrations, this transcript is detected only in the presence of CRP (lanes 3-6), although some transcript is generated in the absence of CRP as the RNA polymerase concentration is increased (lanes 7-12). At even higher concentrations of $E \sigma^{28}$, transcription becomes completely independent of CRP (data not shown). The aer transcript generated by $E \sigma^{28}$ is not detected in reactions using $\mathrm{E} \sigma^{70}$ (Fig. $3 \mathrm{~A}$, lanes 13 and 14). Instead, a single CRP-independent transcript is produced, which corresponds to the 108-base RNAI control transcript that originates from the pSR replication origin.
To confirm that in vitro transcription initiates from the same promoter defined in our in vivo experiments, promoter unwinding by RNA polymerase was monitored by using $\mathrm{KMnO}_{4}$ to probe for single-stranded regions of DNA (Fig. 3B). In the presence of $\mathrm{E}^{28}$ (lanes 3 and 4), $\mathrm{KMnO}_{4}$ reactive bands appeared from positions -10 to +4 , indicative of promoter melting around the -10 element of the $\sigma^{28}$-dependent promoter highlighted in Fig. 2B. This was observed both in the presence and in the absence of CRP, which is consistent with our finding that transcription initiation by $E \sigma^{28}$ is independent of CRP in vitro at the high RNA polymerase concentrations used in these reactions. Incubation with $\mathrm{E \sigma}^{70}$ did not result in promoter melting around the aer transcript start site, either in the presence or in the absence of CRP (Fig. 3B, lanes 5 and 6). Taken together, the in vitro data confirm that aer is transcribed from a single, $\sigma^{28}$-dependent promoter that is activated by CRP when the RNA polymerase concentration is limited. The observation that the aer promoter becomes less dependent on CRP at higher RNA polymerase concentrations suggests that CRP activates transcription by recruitment of RNA polymerase (Rhodius et al., 1997).

\section{Transcription activation at the aer promoter requires CRP binding at an atypical location}

Mutational analysis showed that CRP-dependent activation of the aer200::lac $Z$ fusion requires CRP binding to the single DNA target indicated in Fig. $2 \mathrm{~B}$ (Hollands et al., 2007). This target site is centred $49.5 \mathrm{bp}$ upstream from the transcript start site, which falls between the typical Class I location of position -61.5 and the Class II location of position -41.5 . To investigate whether CRP can activate $\sigma^{28}$-dependent transcription from positions -41.5 or -61.5 at the aer promoter, we constructed a deletion or insertion in the aer200 fragment to make the 
A

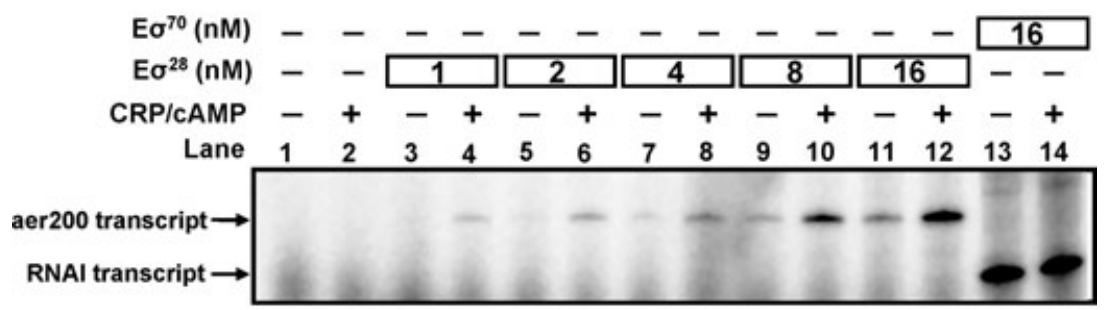

B

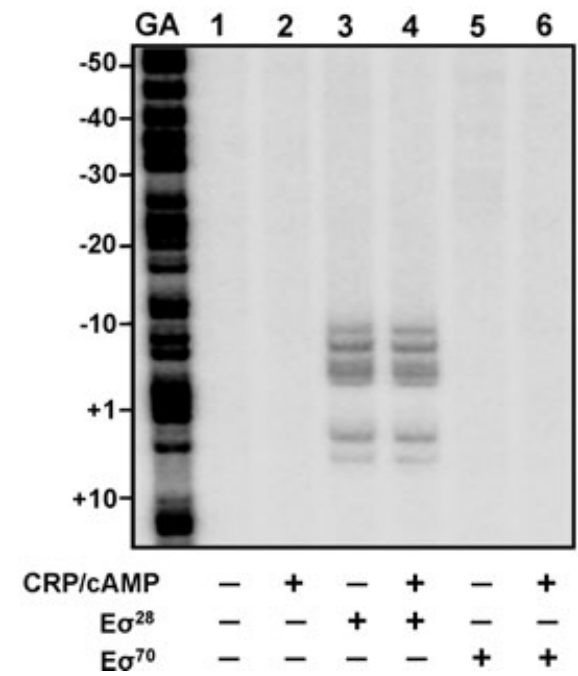

Fig. 3. Sigma factor selectivity and effect of CRP at the aer promoter in vitro.

A. In vitro transcription from the aer promoter. The figure shows the transcripts produced in multi-round in vitro transcription assays using the aer200 fragment cloned in pSR, incubated with various concentrations of $\mathrm{E}^{28}$ or $\mathrm{E}^{70}$ and in the presence or absence of $100 \mathrm{nM}$ $\mathrm{CRP}$ and $0.2 \mathrm{mM}$ cAMP, as indicated. The locations of the $\sigma^{28}$-dependent aer transcript and the $\sigma^{70}$-dependent RNAI control transcript are indicated.

B. Open complex formation at the aer promoter. The figure shows the results of $\mathrm{KMnO}_{4}$ footprinting using an aer200

Pstl-HindllI fragment, end-labelled on the template strand and incubated with a final

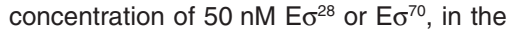
presence or absence of $100 \mathrm{nM}$ CRP and $0.2 \mathrm{mM}$ cAMP, as indicated. The gel was calibrated using a Maxam-Gilbert ' $G+A$ ' sequencing reaction, and is numbered with respect to the aer transcript start site. aer212 and aer211 fragments (Fig. 4, upper three panels). These fragments were cloned into pRW50, and expression of the resulting promoter::lac $Z$ fusions was measured in the $\mathrm{CRP}^{+} \mathrm{FliA}^{+}, \mathrm{CRP}^{-} \mathrm{FliA}^{+}$and $\mathrm{CRP}^{+} \mathrm{FliA}^{-}$ backgrounds. The results illustrated in Fig. 4 show that, when the DNA site for CRP is moved to position -41.5 , aer promoter activity in the $\mathrm{CRP}^{+} \mathrm{FliA}^{+}$strain is reduced to a similar level to that observed in the absence of CRP

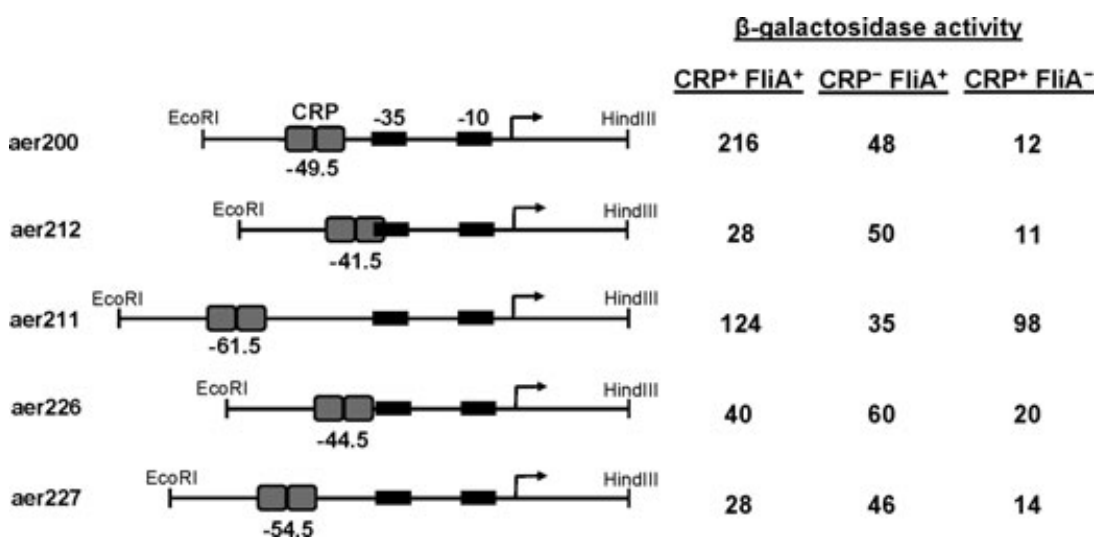

Fig. 4. Effect of moving the DNA site for CRP on activation of the aer promoter. The figure shows schematic diagrams of the wild-type aer200 promoter fragment, and derivatives in which the DNA site for CRP has been moved to position -41.5 (aer212), -61.5 (aer211), -44.5 (aer226) or -54.5 (aer227). The transcript start sites are indicated by arrows, the locations of the promoter -10 and -35 elements are indicated by black rectangles and the DNA site for CRP is shaded grey. The figure also shows the $\beta$-galactosidase activities (in Miller units) measured in strain M182 $\Delta$ fliA containing pKXH100 $\left(\mathrm{CRP}^{+} \mathrm{FliA}^{+}\right)$, strain M182 $\Delta$ fliA $\Delta$ crp containing pKXH100 (CRP- FliA $\left.\mathrm{A}^{+}\right)$or strain M182 $\Delta$ fliA containing 'empty' $\mathrm{pET} 21 \mathrm{a}\left(\mathrm{CRP}^{+} \mathrm{FliA}^{-}\right)$, each carrying the different aer promoter::lacZ fusions cloned in pRW50. Cells were grown to late exponential phase $\left(\mathrm{OD}_{650} 0.9-1.1\right)$ in $\mathrm{LB}$ medium. Data shown are averages from three independent experiments, with a standard deviation of less than $10 \%$. 
or $\sigma^{28}$. This indicates that CRP cannot activate transcription from the aer promoter when bound at a Class II location. Moving the CRP site to position -61.5 (aer211) results in a twofold decrease in promoter activity, but, while the residual promoter activity is dependent on CRP, it is independent of $\sigma^{28}$. The most likely explanation for this is that, here, CRP is activating transcription from an alternative cryptic $\sigma^{28}$-independent promoter. For example, in the aer211 fragment, a $6 \mathrm{bp}$ sequence, 5'-TAAAGA-3', is located 32 bp downstream of the DNA site for CRP and this may well generate a weak Class II CRP-dependent promoter served by $E \sigma^{70}$ (recall that the consensus -10 hexamer for $E \sigma^{70}$ is $5^{\prime}$-TATAAT- $3^{\prime}$ ).

Next, we used the same system to monitor the effects of making a 5 bp deletion or insertion between the DNA site for CRP and the -35 element at the aerpromoter. Both the deletion, which moved the DNA site for CRP to position -44.5 (aer226), and the insertion, which moved the DNA site for CRP to position -54.5 (aer227), resulted in a reduction in promoter activity in the $\mathrm{CRP}^{+} \mathrm{FliA}^{+}$strain to the basal level observed in the absence of CRP (Fig. 4, lower two panels). This indicates that CRP is unable to activate transcription from the aer promoter when its DNA site is moved to the opposite face of the DNA helix. These experiments argue that optimal activation of $\sigma^{28}$-dependent transcription requires CRP binding at position -49.5 .

\section{Location of RNA polymerase $\alpha$ C-terminal domains at the aer promoter}

Activation by CRP at both Class I and Class II $\sigma^{70}$. dependent promoters requires a contact between CRP activating region 1 (AR1) and $\alpha$ CTD. Previous work showed that CRP-dependent activation at the aer promoter also requires AR1 (Hollands et al., 2007), which likely functions by contacting $\alpha C T D$ in $E \sigma^{28}$. Because the organization of the aer promoter is unlike that at Class I or Class II CRP-dependent promoters, it is unclear whether the interaction between AR1 and $\alpha$ CTD occurs via the upstream or downstream subunit of dimeric CRP bound at the promoter. To address this, we mapped the location of $\alpha C T D$ binding at the aer promoter using purified RNA polymerase that had been labelled with the chemical nuclease reagent iron [S]-1-[p-bromoacetamidobenzyl] ethylenediaminetetraacetate (FeBABE) on a single cysteine residue at position 302 in the $\alpha$ CTDs (see Experimental procedures). Transcriptionally competent open complexes were formed using the end-labelled aer200 promoter fragment, purified $\mathrm{CRP}$ and FeBABE-tagged $E \sigma^{28}$, and DNA cleavage by FeBABE was triggered. Analysis of the pattern of DNA cleavage by gel electrophoresis reveals the location of the $\alpha$ CTDs at the aer promoter. Note that, in this assay, in most cases, a single Fe-BABE-labelled $\alpha$ CTD will give rise to cleavages in two adjacent minor grooves, as a wave of hydroxyl radicals generated from the Fe-BABE impinges on the target DNA (Lee et al., 2003).

Results presented in Fig. 5A show that, in the presence of CRP and $E \sigma^{28}$ (lane 3), DNA cleavage on the template strand of the aer promoter is enhanced around positions -72 and -64 upstream of the DNA site for CRP, and around positions -38 and -30 downstream of the CRP site. This indicates that the $\alpha$ CTDs can contact the DNA both upstream and downstream of the bound CRP dimer. In the presence of $E \sigma^{28}$, but in the absence of CRP (lane 2), the pattern of DNA cleavage is similar to the background detected in the absence of any protein (lane 1). This suggests that the two $\alpha$ CTDs are positioned at their targets on the DNA only in the presence of CRP. Interestingly, the spacing between the centre of the DNA site for CRP and the downstream FeBABE-induced DNA cleavage at the aer promoter is identical to that observed by Lee et al. (2003) at a Class I CRP-dependent promoter served by $E \sigma^{70}$ (Fig. 5B and C). Similarly, the spacing between the centre of the DNA site for CRP and the upstream FeBABEinduced DNA cleavage is identical to that seen at a Class II CRP-dependent promoter served by $E \sigma^{70}$ (Lee et al., 2003). Thus, the juxtaposition between the downstreambound $\alpha$ CTD and CRP in open complexes at the aer promoter appears to be identical to the AR1-mediated juxtaposition between downstream-bound $\alpha$ CTD and CRP at a Class I CRP-dependent promoter. Similarly, the juxtaposition between the upstream-bound $\alpha$ CTD and CRP at the aer promoter appears to be identical to the AR1mediated juxtaposition between upstream-bound $\alpha$ CTD and CRP at a Class II CRP-dependent promoter (Fig. 5B and $\mathrm{C}$ ).

In the crystal structure of the CRP- $\alpha$ CTD-DNA complex, $\alpha C T D$ contacts approximately 6 bp of DNA spanning a minor groove, centred 18-19 bp from the centre of the DNA site for CRP (Benoff et al., 2002). The locations of the specific DNA cleavages at the aer promoter are consistent with binding of the $\alpha$ CTDs at sites centred $18.5 \mathrm{bp}$ both upstream and downstream of the DNA site for CRP (Fig. 5B). These sequences are also AT-rich, a feature associated with DNA binding by $\alpha$ CTD (Gourse et al., 2000).

\section{Regulation by CRP at another $\sigma^{28}$-dependent promoter}

To investigate whether CRP directly regulates $E \sigma^{28}$. dependent transcription at other promoters, we used electromobility shift assays to compare the binding of CRP to end-labelled DNA fragments covering the regulatory regions of aer and the seven other $\sigma^{28}$-dependent operons from E. coli K-12 strain MG1655 described by Zhao et al. (2007). The results, illustrated in Fig. 6, show that CRP binds to a single site in the aer200 fragment, but binding 
A

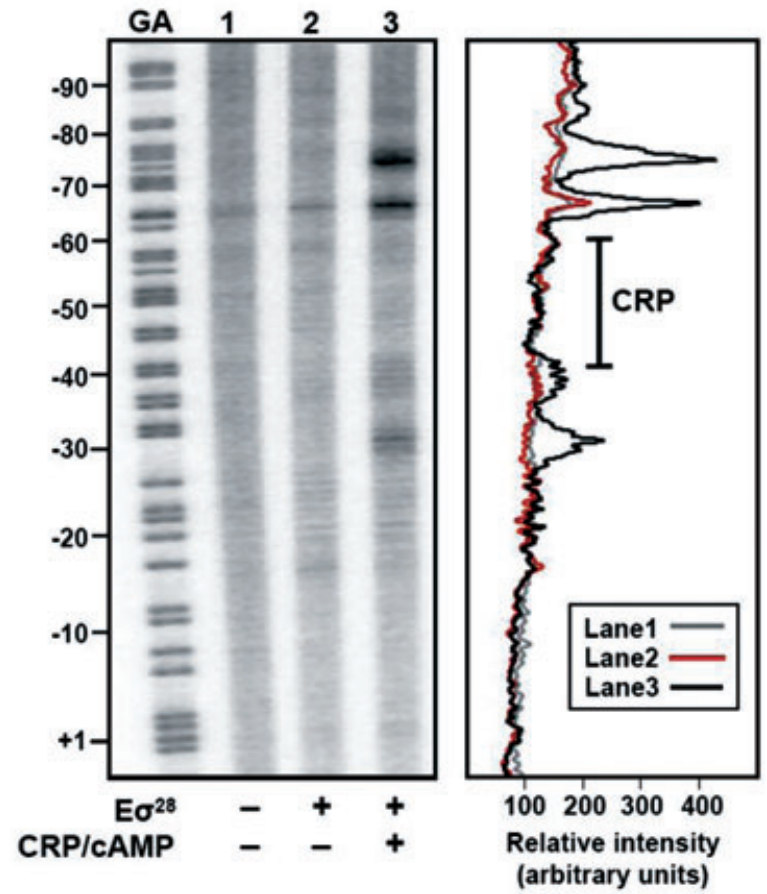

B

aer

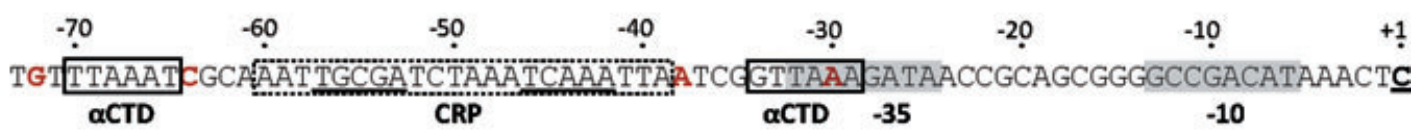

C

$\begin{array}{llllll}-80 & -70 & -60 & -50 & -40 & -30\end{array}$

CC (-61.5) p12T CCGGGATCAGGIAAATGTGATGTACATCACATGGATCDGATCGATGTTTAAAGATCCCCCCTCACTCCTGCC

$\mathrm{CC}(-41.5)$

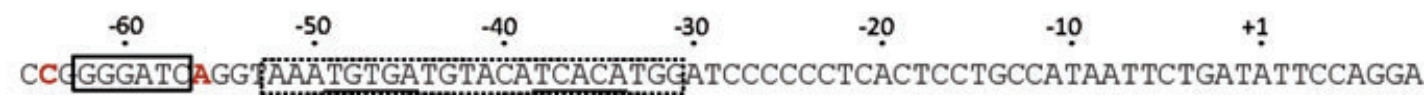

Fig. 5. Mapping the location of the RNA polymerase $\alpha$ C-terminal domains at the aer promoter.

A. The figure shows the results of FeBABE footprinting using the aer200 promoter fragment, and $\mathrm{E}^{28}$ tagged with FeBABE at position 302 of the $\alpha \mathrm{C}$-terminal domain. The Pstl-Hindlll promoter fragment, end-labelled on the template strand, was incubated in the presence or absence of $200 \mathrm{nM}$ FeBABE-tagged $\mathrm{E}^{28}$ and $100 \mathrm{nM}$ CRP/0.2 mM CAMP, as indicated. The left hand panel shows an autoradiograph of the $6 \%$ polyacrylamide sequencing gel on which the reactions were run. The gel was calibrated using a Maxam-Gilbert ' $G+A$ ' sequencing reaction, and is numbered with respect to the aer transcript start site. The right hand panel shows a plot of the relative intensity of bands down each lane of the gel, with the position of the DNA site for CRP indicated.

B. Sequence of the aer promoter region, showing the proposed locations of $\alpha$ CTD binding. The -10 and -35 elements of the $\sigma^{28}$-dependent promoter are shaded grey, the DNA site for CRP is denoted by the dashed box, and the locations of FeBABE-induced DNA cleavage are highlighted in red. The sites where the $\alpha$ CTDs are proposed to contact the DNA ( 6 bp sequences centred 18-19 bp from the centre of the DNA site for CRP (Benoff et al., 2002)) are indicated by the solid boxes. The sequence is numbered with respect to the aer transcript start site.

C. Proposed locations of $\alpha$ CTD binding at the model Class I and Class II CRP-dependent promoters described by Lee et al. (2003). At each promoter, the DNA site for CRP is denoted by a dashed box, and the locations of FeBABE-induced DNA cleavage are highlighted in red. The sites where $\alpha$ CTD is proposed to contact the DNA are indicated by the solid boxes.

of CRP to specific targets in the tsr and trg regulatory regions was also detected. Note that bioinformatic analyses had predicted DNA sites for CRP upstream of both tsr and trg (Robison et al., 1998). The trg promoter fragment binds CRP with similar affinity to the aer fragment, while CRP binding to the tsr fragment is much tighter. No clear binding of CRP was found with the fliC/fliD, flgMN, flgKL, motAB/cheAW or tar/tap/cheRBYZ fragments.
The action of CRP at the tsr and trg regulatory regions was studied further. In the tsr regulatory region, the predicted CRP site is located $132.5 \mathrm{bp}$ upstream of the $\sigma^{28}$ dependent $t s r$ promoter, so it is unlikely that CRP makes direct contact with bound $E \sigma^{28}$. Indeed, no direct effect of CRP on gene expression from the tsr regulatory region could be detected (K. Hollands, unpubl. data). In contrast, alignment of the DNA sequences of the trg and aer regu- 


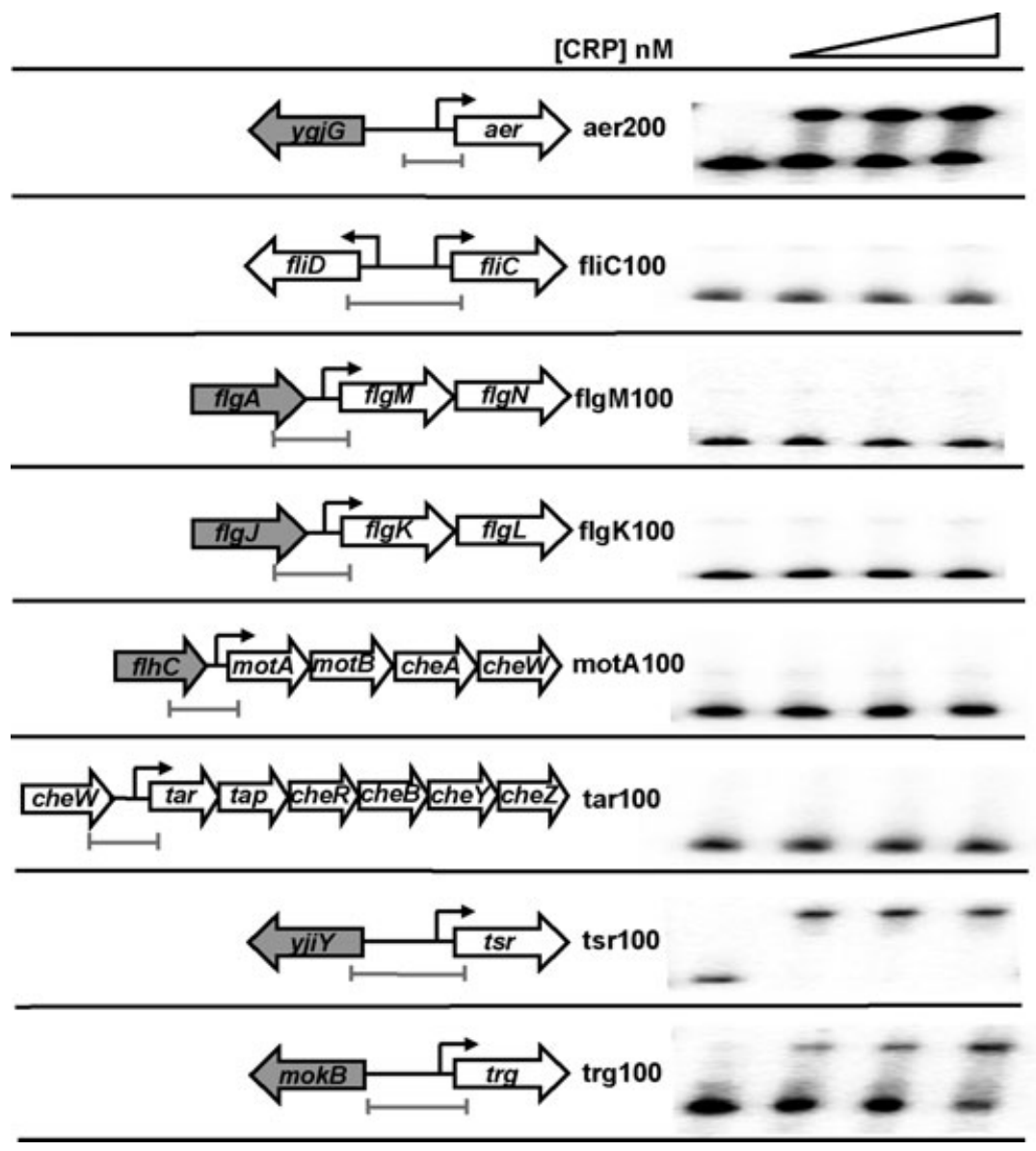

Fig. 6. Binding of CRP to $\sigma^{28}$-dependent promoters in vitro. The left hand panels show schematic diagrams of the regulatory regions of the eight well characterized $\sigma^{28}$-dependent promoters from E. coli K-12 (not to scale). $\sigma^{28}$-dependent genes are indicated by open arrows, while genes that are not known to be $\sigma^{28}$-dependent are shown as grey arrows. Black lines denote intergenic regions, and black arrows show the locations of known or putative $\sigma^{28}$-dependent promoters. Grey bars indicate the extent of the EcoRI-HindIII promoter fragments used in this work. The right hand panels show the results of electromobility shift assays using the end-labelled promoter fragments, incubated with $0,50,100$ or $200 \mathrm{nM}$ CRP, in the presence of $0.2 \mathrm{mM}$ cAMP. latory regions revealed that the spacing between the predicted DNA sites for CRP and the different elements of the two $\sigma^{28}$-dependent promoters is identical (Fig. 7A).

To measure the effect of CRP on expression from the trg regulatory region, the trg100 promoter fragment was cloned into pRW50, and the activity of each promoter ::lacZ fusion was measured in the $\mathrm{CRP}^{+} \mathrm{FliA}^{+}, \mathrm{CRP}^{-} \mathrm{FliA}^{+}$ and $\mathrm{CRP}^{+} \mathrm{FliA}^{-}$backgrounds. Recall that, in the conditions used in our experiments, direct effects of CRP on transcription of promoter::lacZ fusions in pRW50 can be measured independent of the effect of CRP on $\sigma^{28}$ levels. Results illustrated in Fig. 7B indicate that expression from the trg regulatory region, like the aer promoter, is dependent on $\sigma^{28}$ and is activated by CRP. The conservation of the spacing between the DNA site for CRP and the -10 and -35 elements at the aer and trg promoters suggests that the mechanisms of transcription activation at the two promoters are similar. Interestingly, the trg and aer genes encode homologous proteins with similar functions. While Aer is an energy sensor that controls responses to redox signals, Trg is a chemosensor that responds to the monosaccharides ribose and galactose (Taylor et al., 1999).

\section{Conclusions}

Here we have described the first examples of direct activation by CRP of promoters served by RNA polymerase holoenzyme containing the flagellar sigma factor, $\sigma^{28}$. We showed that transcription of the E. coli K-12 aer gene is driven by a single $\sigma^{28}$-dependent promoter, which is activated by CRP binding to a single site positioned 49.5 base pairs upstream of the transcript start site. This location appears optimal for activation. This is in contrast to the situation at previously studied Class I and Class II CRPdependent promoters where the optimal locations for activation by CRP are positions -61.5 and -41.5 respectively, and where CRP activates only very weakly when bound to a site centred near position -50 (Gaston et al., 1990). Our results argue that the spacing requirements for CRPdependent activation at promoters served by $E \sigma^{28}$ differ from those at promoters served by $E \sigma^{70}$. It is possible that promoters recognized by some other alternative $\sigma$ factors also require $\mathrm{CRP}$ binding at unusual locations. For example, at the $\sigma^{38}$-dependent $c s i D$ promoter, CRP activates optimally from a DNA site centred at position -68.5 (Germer et al., 2001). From this position, or a site located 
A
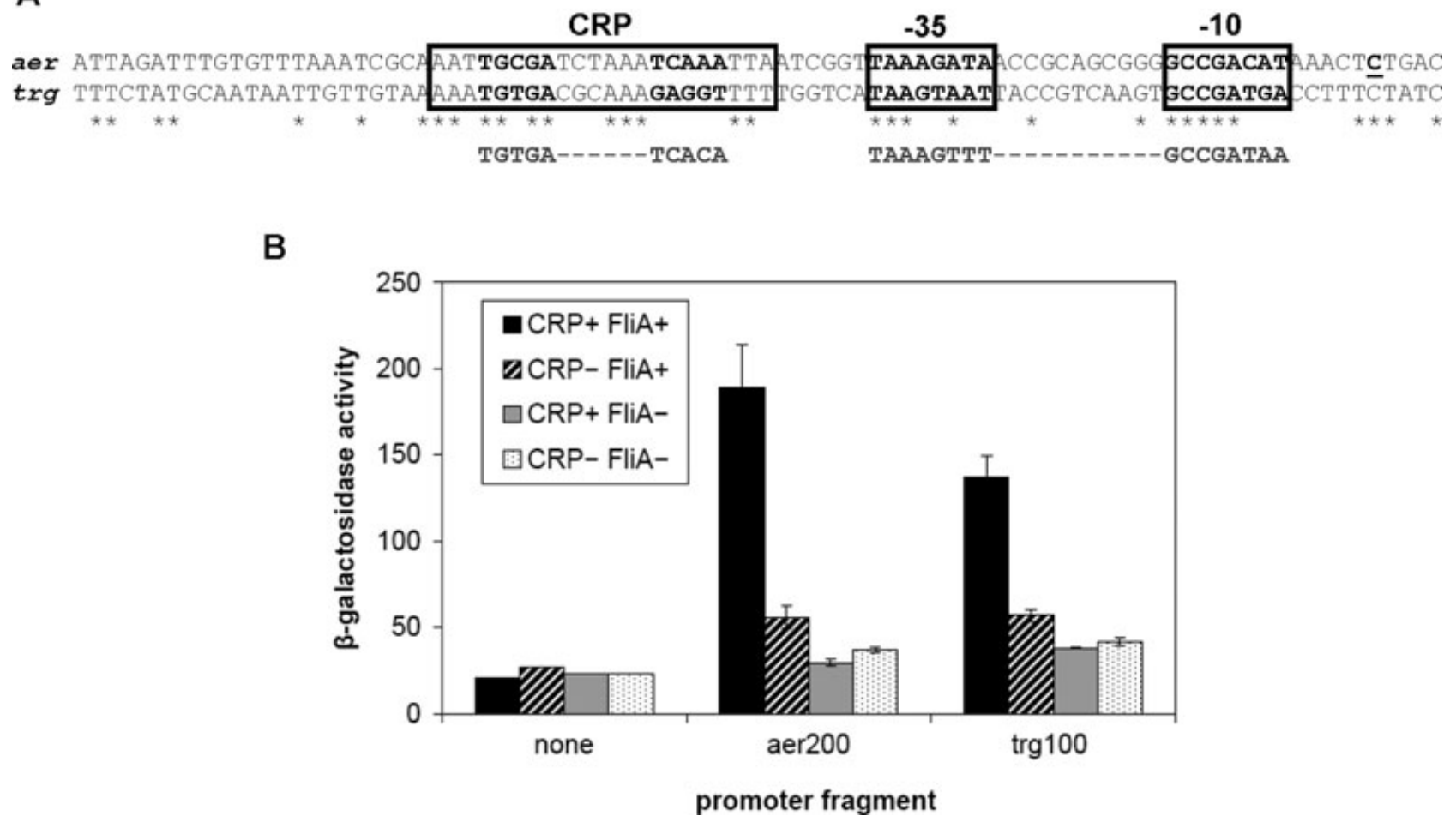

Fig. 7. Activation of the $\sigma^{28}$-dependent trg promoter by CRP.

A. Sequence alignment of the aer and trg regulatory regions. The -10 and -35 elements of the $\sigma^{28}$-dependent aer and trg promoters, and the DNA sites for CRP, are highlighted. The consensus sequences for CRP and E $\sigma^{28}$ binding (Busby and Ebright, 1999; Koo et al., 2009) are shown below the alignment. Asterisks below the sequence specify bases that are identical in the two sequences.

B. Effect of CRP on expression from the trg promoter. The figure shows $\beta$-galactosidase activities (in Miller units) measured in strain M182 $\Delta$ fliA containing pKXH100 $\left(\mathrm{CRP}^{+} \mathrm{FliA}^{+}\right)$, strain M182 $\Delta$ fliA $\Delta$ crp containing pKXH100 (CRP $\left.{ }^{-} \mathrm{FliA}^{+}\right)$, strain M182 $\Delta$ fliA containing 'empty' pET21a $\left(\mathrm{CRP}^{+} \mathrm{Fli} \mathrm{A}^{-}\right)$or strain M182 $\triangle$ fliA $\Delta$ crp containing 'empty' pET21a (CRP- Fli $\left.\mathrm{A}^{-}\right)$, each carrying the trg100::lacZ fusion cloned in pRW50. pRW50 carrying the pUC9 linker was included as a negative control ('none'), and the aer200::lacZ fusion, cloned in pRW50, was included as a positive control. Data shown are averages from three independent experiments, and error bars indicate one standard deviation.

one helical turn upstream, CRP can activate $\sigma^{38}$-, but not $\sigma^{70}$-dependent transcription.

Activation at the aer promoter requires AR1 of CRP that likely contacts $\alpha$ CTD (Hollands et al., 2007). Our results show that the two $\alpha C T D$ s of $E \sigma^{28}$ contact DNA both upstream and downstream of CRP, although note that we cannot prove that both contacts occur simultaneously. The finding that one $\alpha$ CTD binds downstream of CRP at the aer promoter was surprising. Structural modelling of the CRP-RNA polymerase-DNA complex at a Class I promoter, where the DNA site for CRP is centred at position -61.5 , indicates that one $\alpha C T D$ is tightly sandwiched between CRP and $\sigma^{70}$, such that it can simultaneously contact DNA, AR1 on CRP and $\sigma^{70}$ domain 4 (Chen et al., 2003; Lawson et al., 2004). As the DNA site for CRP at the aer promoter is located 12 bp downstream, it appears that there cannot be sufficient space for $\alpha C T D$ to fit between the CRP dimer and the promoter-bound sigma factor. We modelled the structure of the CRP-RNA polymerase-DNA complex at the aer promoter by combining the crystal structure of the CRP- $\alpha$ CTD-DNA complex (Benoff et al.,
2002) with the E$\sigma^{A}$.-fork junction DNA structure (Murakami et al., 2002) and, as expected, we found that there is a clash between the predicted locations of the $\alpha$ CTD downstream of CRP and domain 4 of $\sigma$, which contacts the promoter -35 element (K. Hollands and D.J. Lee, unpublished). This leads us to propose a model in which the organization of the CRP-E $\sigma^{28}$-DNA complex at the aer promoter differs from that of the CRP-E $\sigma^{70}$-DNA complex at a Class I $\sigma^{70}$-dependent promoter (Fig. 8A). Our FeBABE footprinting data indicate that the juxtaposition of $\mathrm{CRP}$ and the downstream $\alpha \mathrm{CTD}$ at the aer promoter is the same as at the Class I promoter. This implies that it must be domain 4 of $\sigma^{28}$ that is positioned differently within the CRP-E $\sigma^{28}$-DNA complex, compared with domain 4 of $\sigma^{70}$ within the CRP-E $\sigma^{70}-\mathrm{DNA}$ complex at a Class I promoter. This is supported by the observation that the -10 and -35 elements at $\sigma^{28}$-dependent promoters are located 2-3 bp closer together than at promoters served by $E \sigma^{70}$ (Fig. 8B), suggesting that the contact site for $\sigma^{28}$ domain 4 on promoter DNA may lie several bases downstream of that for $\sigma^{70}$ domain 4 at a $\sigma^{70}$-dependent promoter. The 
A

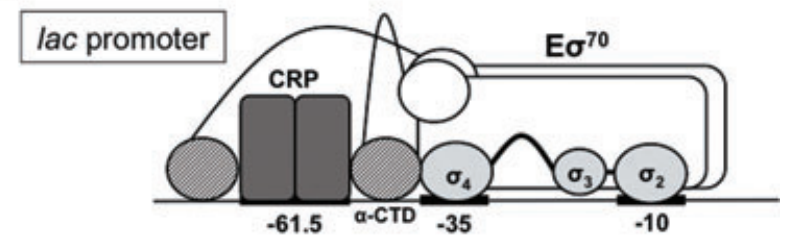

aer promoter

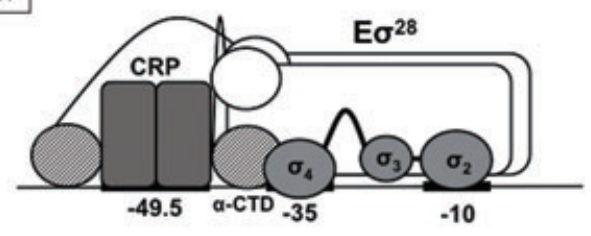

B

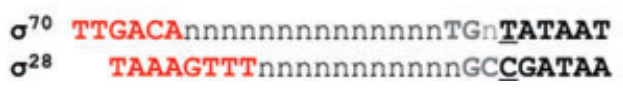

Fig. 8. Organization of the CRP-RNA polymerase-DNA complex at the aer promoter.

A. Comparison of the CRP-RNA polymerase-DNA complexes at $\sigma^{70}$ - and $\sigma^{28}$-dependent promoters. The upper panel shows a schematic diagram of the CRP-E $\sigma^{70}$-DNA ternary complex at the Class I CRP-activated lac promoter, where CRP binds at a site centred $61.5 \mathrm{bp}$ upstream of the transcript start site. The lower panel shows a model for the organization of the CRP-E $\sigma^{28}$-DNA ternary complex at the aer promoter, where CRP binds at a site centred $49.5 \mathrm{bp}$ upstream from the transcript start site. Domain 4 of $\sigma^{28}$ is proposed to contact the DNA further downstream at the aer promoter than does domain 4 of $\sigma^{70}$ at the lac promoter, and this relieves a potential clash with downstream-bound $\alpha$ CTD. B. Spacing between the -10 and -35 elements at $\sigma^{70}$ - and $\sigma^{28}$-dependent promoters. The figure shows the $\sigma^{70}$ and $\sigma^{28}$ promoter consensus sequences, aligned by the position of the upstream edge of the core -10 element (underlined). The core -10 element is shown in black, the extended -10 element in grey and the -35 element in red. Each base in the spacer region is represented by an ' $n$ '.

model, illustrated in Fig. 8A, suggests that domain 4 of $\sigma^{28}$ is offset by rotation and translocation around the surface of the promoter DNA. It is quite possible that this is its 'normal' position at $\sigma^{28}$-dependent promoters, but this will require further experimental evidence.

Although E. coli contains hundreds of transcription activators, there are few examples of factor-dependent activation of promoters recognized by alternative $\sigma$ factors such as $\sigma^{28}$. Transcription from promoters served by alternative $\sigma$ factors is mostly regulated by controlling the expression and activity of the $\sigma$ factor itself, and by the very stringent promoter recognition properties of the alternative $\sigma$ factors. It is generally accepted that control over most flagellar genes is exerted by regulating the expression and activity of FlhDC, $\sigma^{28}$, and the anti- $\sigma$ factor, FlgM (Chilcott and Hughes, 2000; Keseler et al., 2009). Our findings show that transcription activators can also play an important role in controlling transcription by $E \sigma^{28}$.
The similar organization of the aer and trg promoters suggests a common mechanism of direct activation by CRP. However, we found no evidence for direct regulation by CRP at the six other well-characterized $\sigma^{28}$-dependent promoters in E. coli K-12. This raises the question of why CRP should directly regulate transcription of aer and trg, particularly when CRP indirectly regulates transcription of all genes in the flagellar cascade by controlling expression of the master regulator, FlhDC. Expression of FlhDC is tightly regulated by multiple transcription factors, including CRP, H-NS and OmpR, and hence the genes of the flagellar cascade are regulated in response to many different environmental inputs (Shin and Park, 1995; Soutourina et al., 1999). It is possible that expression of aer and $\operatorname{trg}$ is required only in response to conditions that induce CRP activity and not in response to other signals that induce the flagellar cascade. Alternatively, expression of aer and trg may need to be upregulated to a greater extent than other genes when CRP activity is induced. This may be particularly important when levels of $E \sigma^{28}$ are low. In these conditions, recruitment of $\mathrm{E}^{28}$ by CRP may ensure that the aer and trg transcription units are preferentially expressed compared with other $\sigma^{28}$-dependent genes. Note that aer and trg encode homologous methylaccepting chemotaxis regulator-type proteins, which interact with the flagellar motor via the $\mathrm{CheA} / \mathrm{CheY}$ signalling pathway to control the direction of bacterial movement in response to different chemical or energetic signals (Taylor et al., 1999). The direct involvement of CRP in their regulation may therefore simply be a reflection of the role of CRP in facilitating the acquisition and metabolism of nutrients other than glucose (Kolb et al., 1993).

\section{Experimental procedures}

\section{Strains, plasmids and promoter constructs}

The E. coli K-12 strains, plasmids and promoter fragments used in this study are listed in Table 2. Standard recombinant DNA techniques were used throughout and all the oligonucleotide primers used are listed in Table S1.

The $\Delta$ fliA derivatives of strains M182 and M182 $\Delta$ crp were constructed by $\mathrm{P} 1$ transduction of a fliA::kan mutation from strain JW1907-1. The kanamycin resistance marker was subsequently removed by expressing the FLP recombinase from plasmid pCP20, as described by Cherepanov and Wackernagel (1995), and the presence of the deletion was confirmed by colony PCR using primers D56550 and D56551.

Plasmid pKXH100 was constructed by cloning an NdelXhol fragment carrying the fliA coding sequence from $E$. coli K-12 strain MG1655, amplified by PCR using primers D57845 and D57846, into plasmid pET21a (Novagen). As a result of leaky expression, genes cloned under the control of the T7 promoter in pET21a are expressed even in strains that do not produce T7 RNA polymerase, including M182 (Wu et al., 2005). This activity is independent of the presence of the inducer IPTG (K. Hollands, unpubl. results). 
Table 2. Strains and plasmids and promoter fragments.

\begin{tabular}{|c|c|c|}
\hline Name & Description & Reference \\
\hline \multicolumn{3}{|l|}{ E. coli K-12 strains } \\
\hline MG1655 & $\mathrm{F}^{-} \lambda^{-}$ilvG rfb-50 rph-1 & Blattner et al. (1997) \\
\hline JW1907-1 & fliA::kan rrnB3 $\Delta / a c Z 4787$ hsdR514 $\Delta($ araBAD) $567 \Delta($ rhaBAD $) 568$ rph-1 & Baba et al. (2006) \\
\hline M182 & lacX74 galK galU strA & Casadaban and Cohen (1980) \\
\hline M182 $\Delta c r p$ & $\Delta$ crp lacX74 galK galU strA & Busby et al. (1983) \\
\hline M182 $\Delta$ fliA & $\triangle$ fliA lacX74 galK galU strA & This study \\
\hline M182 $\Delta$ crp $\Delta f l i A$ & $\Delta$ fliA $\triangle$ crp lacX74 galK galU strA & This study \\
\hline BL21(DE3) & $\mathrm{F}^{-}$ompT $h s d S_{B}\left(r_{B}^{-} m_{B}^{-}\right)$gal dcm $\lambda(\mathrm{DE} 3$ [lacl lacUV5-T7 gene 1 ind1 sam7 nin5]) & Studier and Moffat (1986) \\
\hline \multicolumn{3}{|c|}{ 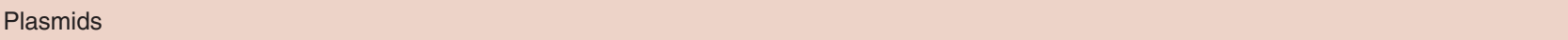 } \\
\hline pRW50 & $\begin{array}{l}\text { Broad-host-range lac } Z \text { expression vector used for cloning EcoRI-HindlII } \\
\text { promoter fragments; contains the RK2 origin of replication and encodes } \mathrm{Tc}^{\mathrm{R}}\end{array}$ & Lodge et al. (1992) \\
\hline pSR & $\begin{array}{l}\text { pBR322 derivative, used for cloning EcoRI-HindIII promoter fragments } \\
\text { upstream of the } \lambda \text { oop terminator }\end{array}$ & Kolb et al. (1995) \\
\hline pET21a & Protein overexpression vector & Novagen \\
\hline $\mathrm{pKXH100}$ & pET21a carrying fliA gene cloned on an Ndel-Xhol fragment & This study \\
\hline \multicolumn{3}{|l|}{ Promoter fragments ${ }^{a}$} \\
\hline aer200 & 168 bp EcoRI-HindllI fragment carrying the aer regulatory region & Hollands et al. (2007) \\
\hline aer206 & $\begin{array}{l}\text { Derivative of aer200 with CGA to GCT changes from positions }-11 \text { to }-9 \\
\text { in the promoter }-10 \text { element }\end{array}$ & This study \\
\hline aer213 & $\begin{array}{l}\text { Derivative of aer200 with a } \mathrm{T} \text { to } \mathrm{C} \text { substitution at position }-32 \text { in the promoter } \\
-35 \text { element }\end{array}$ & This study \\
\hline aer214 & $\begin{array}{l}\text { Derivative of aer200 with an A to T substitution at position }-30 \text { in the promoter } \\
-35 \text { element }\end{array}$ & This study \\
\hline aer224 & $\begin{array}{l}\text { Derivative of aer200 with a } \mathrm{G} \text { to } \mathrm{A} \text { substitution at position }-28 \text { in the promoter } \\
-35 \text { element }\end{array}$ & This study \\
\hline aer212 & Derivative of aer200, in which the DNA site for CRP is moved to position -41.5 & This study \\
\hline aer211 & Derivative of aer200, in which the DNA site for CRP is moved to position -61.5 & This study \\
\hline aer226 & Derivative of aer200, in which the DNA site for CRP is moved to position -44.5 & This study \\
\hline aer227 & Derivative of aer200, in which the DNA site for CRP is moved to position -54.5 & This study \\
\hline fliC100 & EcoRI-HindIII fragment carrying the regulatory region of the fliC operon & This study \\
\hline flgM100 & EcoRI-HindIII fragment carrying the regulatory region of the flgMN operon & This study \\
\hline flgK100 & EcoRI-HindIII fragment carrying the regulatory region of the flgKL operon & This study \\
\hline motA100 & EcoRI-HindIII fragment carrying the regulatory region of the motABcheAW operon & This study \\
\hline $\operatorname{tar} 100$ & $\begin{array}{l}\text { EcoRI-HindIII fragment carrying the regulatory region of the tar tap cheRB } \\
\text { cheYZfIgMN operon }\end{array}$ & This study \\
\hline tsr100 & EcoRI-HindlII fragment carrying the regulatory region of the tsr operon & This study \\
\hline $\operatorname{trg} 100$ & EcoRI-HindllI fragment carrying the regulatory region of the trg operon & This study \\
\hline
\end{tabular}

a. The base sequence of each of the promoter fragments is shown in Fig. S2.

The DNA sequence of each promoter fragment is shown in Fig. S2. Promoter fragments were amplified by PCR from genomic DNA of E. coli K-12 strain MG1655, using primers that introduce flanking EcoRI and Hindlll sites (listed in Table S1). For promoter activity assays, EcoRI-HindIII fragments were cloned into the lac expression vector, pRW50. To construct templates for in vitro transcription assays, and to generate DNA fragments for electromobility shift assays and footprinting, promoter fragments were cloned into plasmid pSR. Derivatives of the aer200 fragment carrying point mutations in the -10 or -35 elements (aer206, aer213, aer214 and aer224) were constructed by megaprimer PCR. In a firstround PCR reaction, a megaprimer was synthesized from pSR/aer200 as a template, using a mutagenic primer carrying the desired mutation, and a flanking primer (either D51598 or D53041: see Table S1). The megaprimer was then used in a second-round PCR with the opposing flanking primer and pSR/aer200 as a template to generate a full-length promoter fragment containing the required mutation, which was then cloned into pRW50. The aer212, aer211, aer226 and aer227 fragments were constructed by inserting or deleting DNA between the DNA site for CRP and the -35 element of the aer promoter. First, two PCR products were synthesized using pSR/aer200 as a template: one generated using upstream primer D53041 and a downstream primer carrying the insertion or deletion, and a second generated using the downstream primer D51598 and an upstream primer carrying the insertion or deletion (see Table S1). The two PCR products were then annealed via their 26-32 bp overhangs, and the two strands were extended using DNA polymerase to generate a full-length promoter fragment carrying the insertion or deletion. This product was then amplified by PCR using primers D53041 and D51598 and cloned into pRW50.

\section{$\beta$-Galactosidase assays}

$\beta$-Galactosidase levels in cells carrying promoter::lacZ fusions, cloned in pRW50, were measured using the method of Miller (1972). Cells were grown aerobically at $37^{\circ} \mathrm{C}$ in LB 
medium. Activities are shown in Miller units (nmol ONPG hydrolysed $\mathrm{min}^{-1} \mathrm{mg}^{-1}$ dry cell mass), and are averages from at least three independent experiments.

\section{Primer extension}

Transcript start sites were mapped by primer extension as described in Lloyd et al. (2008), using RNA purified from strain M182 carrying the aer200 promoter fragment cloned in pRW50 and 5' end-labelled primer D49724, which anneals downstream of the HindlII site in pRW50. Primer extension products were analysed on denaturing $6 \%$ polyacrylamide gels, calibrated with sequencing reactions, and were visualized using a Fuji phosphor screen and Bio-Rad Molecular Imager FX.

\section{Protein purification}

Purified CRP protein was donated by David Grainger (University of Warwick, UK), and wild type E. coli core RNA polymerase was purchased from Epicentre Technologies (Madison, WI). His-tagged RNA polymerase $\alpha$ subunits containing a single cysteine residue at position 302 were prepared and labelled with FeBABE as described by Lee et al. (2003). FeBABE-tagged $\alpha$ subunits were incorporated into core RNA polymerase using the reconstitution method of Tang et al. (1995). Purified $\sigma^{28}$ and $\sigma^{70}$ proteins were prepared from BL21(DE3) cells carrying the overexpression plasmid pKXH100, as described by Grainger et al. (2008). E $\sigma^{28}$ and $E \sigma^{70}$ holoenyzmes were made by mixing wild type or FeBABE-labelled core RNA polymerase with an equimolar amount of $\sigma^{28}$ or $\sigma^{70}$, and incubating for $20 \mathrm{~min}$ at room temperature.

\section{In vitro transcription assays}

Caesium chloride preparations of pSR carrying the aer200 promoter fragment served as a template for multiple-round in vitro transcription assays, as described by Savery et al. (1998). $20 \mathrm{ng}$ pSR/aer200 was incubated in transcription buffer containing $40 \mathrm{mM}$ Tris $\mathrm{pH} 7.9,10 \mathrm{mM} \mathrm{MgCl}, 1 \mathrm{mM}$ dithiothreitol, $100 \mathrm{mM} \mathrm{KCl}, 100 \mu \mathrm{g} \mathrm{ml}^{-1}$ bovine serum albumin, $200 \mu \mathrm{M}$ GTP, $200 \mu \mathrm{M}$ ATP, $200 \mu \mathrm{M}$ CTP, $10 \mu \mathrm{M}$ UTP and $5 \mu \mathrm{Ci}\left[\alpha^{32} \mathrm{P}\right]-$ UTP. Where indicated, CRP was included at $100 \mathrm{nM}$ and CAMP at $0.2 \mathrm{mM}$. Reactions were started by adding $E \sigma^{28}$ or $E \sigma^{70}$. RNA products were analysed on a denaturing $5.5 \%$ polyacrylamide gel and visualized using a Fuji phosphor screen and Bio-Rad Molecular Imager FX.

\section{Footprinting and EMSA experiments}

$\mathrm{KMnO}_{4}$ and FeBABE footprinting experiments were performed on Pstl-Hindlll fragments prepared from caesium chloride preparations of pSR carrying aer200. Fragments were labelled at the HindlII end with $\left[\gamma^{32} \mathrm{P}\right]-\mathrm{ATP}$ using polynucleotide kinase. $\mathrm{KMnO}_{4}$ footprints were performed following the protocol of Browning et al. (2009) and FeBABE footprints were carried out as described by Lee et al. (2003). Each reaction contained approximately $3 \mathrm{nM}$ labelled Pstl-
HindIII DNA fragment in $20 \mathrm{mM} \mathrm{HEPES} \mathrm{pH} \mathrm{8.0,} 5 \mathrm{mM} \mathrm{MgCl}_{2}$, $50 \mathrm{mM}$ potassium glutamate, $1 \mathrm{mM}$ DTT and $0.5 \mathrm{mg} \mathrm{ml}^{-1}$ BSA. $\mathrm{KMnO}_{4}$ footprinting reactions contained $0.2 \mathrm{mM}$ cAMP, $100 \mathrm{nM}$ CRP and $50 \mathrm{nM} E \sigma^{28}$ or $E \sigma^{70}$, as required. FeBABE footprinting reactions contained $0.2 \mathrm{mM}$ CAMP, $100 \mathrm{nM}$ CRP and $200 \mathrm{nM}$ FeBABE-labelled $\mathrm{E}^{28}$. The products of $\mathrm{KMnO}_{4}$ and $\mathrm{FeBABE}$ footprinting reactions were analysed on denaturing $6 \%$ polyacrylamide sequencing gels, calibrated with Maxam-Gilbert ' $G+A$ ' sequencing reactions.

The EMSA experiments were performed using EcoRIHindlll fragments prepared from pSR derivatives, and endlabelled using $\left[\gamma^{32} \mathrm{P}\right]$ ATP and polynucleotide kinase. EMSA reactions were carried out as described by Lloyd et al. (1998) and were analysed on $5 \%$ polyacrylamide gels. Footprinting and EMSA gels were visualized using a Fuji phosphor screen, and analysed using a Bio-Rad Molecular Imager FX and Quantity One software (Bio-Rad).

\section{Acknowledgements}

K.H. was supported by a $\mathrm{PhD}$ studentship from the UK BBSRC and this work was funded by a Wellcome Trust Programme Grant to S.J.W.B.

\section{References}

Baba, T., Ara, T., Hasegawa, M., Takai, Y., Okumura, Y., Baba, M., et al. (2006) Construction of Escherichia coli $\mathrm{K}-12$ in-frame, single-gene knockout mutants: the Keio collection. Mol Syst Biol 2: 2006.0008.

Barembruch, C., and Hengge, R. (2007) Cellular levels and activity of the flagellar sigma factor FliA of Escherichia coli are controlled by FlgM-modulated proteolysis. Mol Microbiol 65: 76-89.

Barrett, C.L., Herring, C.D., Reed, J.L., and Palsson, B.O. (2005) The global transcriptional regulatory network for metabolism in Escherichia coli exhibits few dominant functional states. Proc Natl Acad Sci USA 102: 19103-19108.

Benoff, B., Yang, H., Lawson, C.L., Parkinson, G., Liu, J., Blatter, E., et al. (2002) Structural basis of transcription activation: the CAP-alpha CTD-DNA complex. Science 297: 1562-1566.

Bibikov, S.I., Biran, R., Rudd, K.E., and Parkinson, J.S. (1997) A signal transducer for aerotaxis in Escherichia coli. $J$ Bacteriol 179: 4075-4079.

Blattner, F.R., Plunkett, G., 3rd, Bloch, C.A., Perna, N.T., Burland, V., Riley, M., et al. (1997) The complete genome sequence of Escherichia coli K-12. Science 227: 14531462.

Brown, C.T., and Callan, C.G., Jr (2004) Evolutionary comparisons suggest many novel cAMP response protein binding sites in Escherichia coli. Proc Natl Acad Sci USA 101: 2404-2409.

Browning, D., Savery, N., Kolb, A., and Busby, S.J. (2009) Assays for transcription factor activity. In Methods in Molecular Biology: DNA-Protein Interactions. 3rd edn. Vol. 543. LeBlanc, B., and Moss, T. (eds). Heidelberg: Springer Science, pp. 369-387.

Burgess, R.R., Travers, A.A., Dunn, J.J., and Bautz, E.K. (1969) Factor stimulating transcription by RNA polymerase. Nature 221: 43-46. 
Busby, S., and Ebright, R.H. (1999) Transcription activation by catabolite activator protein (CAP). J Mol Biol 293: 199213.

Busby, S., Kotlarz, D., and Buc, H. (1983) Deletion mutagenesis of the Escherichia coli galactose operon promoter region. J Mol Biol 167: 259-274.

Casadaban, M.J., and Cohen, S.N. (1980) Analysis of gene control signals by DNA fusion and cloning in Escherichia coli. J Mol Biol 138: 179-207.

Chen, H., Tang, H., and Ebright, R.H. (2003) Functional interaction between RNA polymerase alpha subunit C-terminal domain and sigma70 in UP-element- and activatordependent transcription. Mol Cell 11: 1621-1633.

Cherepanov, P.P., and Wackernagel, W. (1995) Gene disruption in Escherichia coli: $\mathrm{Tc}^{\mathrm{R}}$ and $\mathrm{Km}^{\mathrm{R}}$ cassettes with the option of Flp-catalysed excision of the antibiotic-resistance determinant. Gene 158: 9-14.

Chilcott, G.S., and Hughes, K.T. (2000) Coupling of flagellar gene expression to flagellar assembly in Salmonella enterica serovar Typhimurium and Escherichia coli. Microbiol Mol Biol Rev 64: 694-708.

Frye, J., Karlinsey, J.E., Felise, H.R., Marzolf, B., Dowidar, N., McClelland, M., and Hughes, K.T. (2006) Identification of new flagellar genes of Salmonella enterica serovar Typhimurium. J Bacteriol 188: 2233-2243.

Gaston, K., Bell, A., Kolb, A., Buc, H., and Busby, S. (1990) Stringent spacing requirements for transcription activation by CRP. Cell 62: 733-743.

Germer, J., Becker, G., Metzner, M., and Hengge-Aronis, R. (2001) Role of activator site position and a distal UP-element half-site for sigma factor selectivity at a CRP/ $\mathrm{H}$-NS-activated sigma(S)-dependent promoter in Escherichia coli. Mol Microbiol 41: 705-716.

Gosset, G., Zhang, Z., Nayyar, S., Cuevas, W.A., and Saier, M.H., Jr (2004) Transcriptome analysis of CRP-dependent catabolite control of gene expression in Escherichia coli. J Bacteriol 186: 3516-3524.

Gourse, R.L., Ross, W., and Gaal, T. (2000) UPs and downs in bacterial transcription initiation: the role of the alpha subunit of RNA polymerase in promoter recognition. Mol Microbiol 37: 687-695.

Grainger, D.C., Hurd, D., Harrison, M., Holdstock, J., and Busby, S.J. (2005) Studies of the distribution of Escherichia coli cAMP-receptor protein and RNA polymerase along the E. coli chromosome. Proc Natl Acad Sci USA 102: 17693-17698.

Grainger, D.C., Goldberg, M.D., Lee, D.J., and Busby, S.J.W. (2008) Selective repression by Fis and $\mathrm{H}-\mathrm{NS}$ at the Escherichia coli dps promoter. Mol Microbiol 68: 1366-1377.

Gruber, T.M., and Gross, C.A. (2003) Multiple sigma subunits and the partitioning of bacterial transcription space. Annu Rev Micriobiol 57: 441-466.

Hollands, K., Busby, S.J., and Lloyd, G.S. (2007) New targets for the cyclic AMP receptor protein in the Escherichia coli K-12 genome. FEMS Microbiol Lett 274: 89-94.

Ishihama, A. (2000) Functional modulation of Escherichia coli RNA polymerase. Annu Rev Micriobiol 54: 499-518.

Keseler, I.M., Bonavides-Martinez, C., Collado-Vides, J., Gama-Castro, S., Gunsalus, R.P., Johnson, D.A., et al. (2009) EcoCyc: a comprehensive view of Escherichia coli biology. Nucleic Acids Res 37: 464-470.
Kolb, A., Busby, S., Buc, H., Garges, S., and Adhya, S. (1993) Transcriptional regulation by cAMP and its receptor protein. Annu Rev Biochem 62: 749-795.

Kolb, A., Kotlarz, D., Kusano, S., and Ishihama, A. (1995) Selectivity of the Escherichia coli RNA polymerase E sigma 38 for overlapping promoters and ability to support CRP activation. Nucleic Acids Res 23: 819-826.

Koo, B.M., Rhodius, V.A., Campbell, E.A., and Gross, C.A. (2009) Mutational analysis of Escherichia coli sigma28 and its target promoters reveals recognition of a composite -10 region, comprised of an 'extended -10' motif and a core -10 element. Mol Microbiol 72: 830-843.

Lawson, C.L., Swigon, D., Murakami, K.S., Darst, S.A., Berman, H.M., and Ebright, R.H. (2004) Catabolite activator protein: DNA binding and transcription activation. Curr Opin Struct Biol 14: 10-20.

Lee, D.J., Busby, S.J., and Lloyd, G.S. (2003) Exploitation of a chemical nuclease to investigate the location and orientation of the Escherichia coli RNA polymerase alpha subunit C-terminal domains at simple promoters that are activated by the cyclic AMP receptor protein. $J$ Biol Chem 278: 52944-52952.

Lloyd, G.S., Busby, S.J., and Savery, N.J. (1998) Spacing requirements for interactions between the C-terminal domain of the alpha subunit of Escherichia coli RNA polymerase and the cAMP receptor protein. Biochem $J$ 330: 413-420.

Lloyd, G.S., Hollands, K., Godfrey, R.E., and Busby, S.J. (2008) Transcription initiation in the Escherichia coli K-12 mall-malX intergenic region and the role of the cyclic AMP receptor protein. FEMS Micriobiol Lett 288: 250-257.

Lodge, J., Fear, J., Busby, S., Gunasekaran, P., and Kamini, N.R. (1992) Broad host range plasmids carrying the Escherichia coli lactose and galactose operons. FEMS Microbiol Lett 74: 271-276.

Miller (1972) Experiments in Molecular Genetics. Cold Spring Harbor: Cold Spring Harbor Laboratory Press.

Murakami, K.S., Masuda, S., Campbell, E.A., Muzzin, O., and Darst, S.A. (2002) Structural basis of transcription initiation: an RNA polymerase holoenzyme-DNA complex. Science 296: 1285-1290.

Park, K., Choi, S., Ko, M., and Park, C. (2001) Novel sigmaFdependent genes of Escherichia coli found using a specified promoter consensus. FEMS Microbiol Lett 202: 243-250.

Rebbapragada, A., Johnson, M.S., Harding, G.P., Zuccarelli, A.J., Fletcher, H.M., Zhulin, I.B., and Taylor, B.L. (1997) The Aer protein and the serine chemoreceptor Tsr independently sense intracellular energy levels and transduce oxygen, redox, and energy signals for Escherichia coli behaviour. Proc Natl Acad Sci USA 94: 10541-10546.

Rhodius, V.A., West, D.M., Webster, C.L., Busby, S.J., and Savery, N.J. (1997) Transcription activation at class II CRP-dependent promoters: the role of different activating regions. Nucleic Acids Res 25: 326-332.

Robison, K., McGuire, A.M., and Church, G.M. (1998) A comprehensive library of DNA-binding site matrices for 55 proteins applied to the complete Escherichia coli K-12 genome. J Mol Biol 284: 241-254.

Savery, N.J., Lloyd, G.S., Kainz, M., Gaal, T., Ross, W., Ebright, R.H., et al. (1998) Transcription activation at Class 
II CRP-dependent promoters: identification of determinants in the C-terminal domain of the RNA polymerase alpha subunit. EMBO J 17: 3439-3447.

Shin, S., and Park, C. (1995) Modulation of flagellar expression in Escherichia coli by acetyl phosphate and the osmoregulator OmpR. J Bacteriol 177: 4696-4702.

Smith, T., and Hoover, T. (2009) Deciphering bacterial flagellar gene regulatory networks in the genome era. Adv Appl Microbiol 67: 257-295.

Soutourina, O., Kolb, A., Krin, E., Laurent-Winter, C., Rimsky, S., Danchin, A., and Bertin, P. (1999) Multiple control of flagellum biosynthesis in Escherichia coli: role of $\mathrm{H}-\mathrm{NS}$ protein and the cyclic AMP-catabolite activator protein complex in transcription of the flhDC master operon. J Bacteriol 181: 7500-7508.

Studier, F.W., and Moffatt, B.A. (1986) Use of bacteriophage T7 RNA polymerase to direct selective high-level expression of cloned genes. J Mol Biol 189: 113-130.

Tan, K., Moreno-Hagelsieb, G., Collado-Vides, J., and Stormo, G.D. (2001) A comparative genomics approach to prediction of new members of regulons. Genome Res 11: 566-584.

Tang, H., Severinov, K., Goldfarb, A., and Ebright, R.H. (1995) Rapid RNA polymerase genetics: one-day, no-column preparation of reconstituted recombinant Escherichia coli RNA polymerase. Proc Natl Acad Sci USA 92: 4902-4906.

Taylor, B.L., Zhulin, I.B., and Johnson, M.S. (1999) Aerotaxis and other energy-sensing behavior in bacteria. Annu Rev Microbiol 53: 103-128.
Wozniak, C.E., and Hughes, K.T. (2008) Genetic dissection of the consensus sequence for the class 2 and class 3 flagellar promoters. J Mol Biol 379: 936-952.

Wu, T., Malinverni, J., Ruiz, N., Kim, S., Silhavy, T.J., and Kahne, D. (2005) Identification of a multicomponent complex required for outer membrane biogenesis in Escherichia coli. Cell 121: 235-245.

Yu, H.H., Di Russo, E.G., Rounds, M.A., and Tan, M. (2006) Mutational analysis of the promoter recognized by Chlamydia and Escherichia coli sigma28 RNA polymerase. J Bacteriol 188: 5524-5531.

Zhao, K., Liu, M., and Burgess, R.R. (2007) Adaptation in bacterial flagellar and motility systems: from regulon members to 'foraging'-like behavior in E. coli. Nucleic Acids Res 35: 4441-4452.

Zheng, D., Constantinidou, C., Hobman, J.L., and Minchin, S.D. (2004) Identification of the CRP regulon using in vitro and in vivo transcriptional profiling. Nucleic Acids Res 32: 5874-5893.

\section{Supporting information}

Additional supporting information may be found in the online version of this article.

Please note: Wiley-Blackwell are not responsible for the content or functionality of any supporting materials supplied by the authors. Any queries (other than missing material) should be directed to the corresponding author for the article. 